ARCHIVO ESPAÑOL DE ARTE, LXXXI, 323

JULIO-SEPTIEMBRE 2008, pp. 303-306

ISSN: 0004-0428

\title{
UNA OBRA DE GIACOMO ANTONIO PONZANELLI EN EL COMERCIO ANTICUARIO DE MADRID*
}

El pasado año estuvo a la venta en el comercio anticuario de Madrid una bellísima Inmaculada de escuela genovesa firmada por Giacomo Antonio Ponzanelli. La escultura, tallada en mármol de Carrara, mide $112 \mathrm{cms}$. y copia, casi al pie de la letra, la Inmaculada de su maestro Filippo Parodi, en el complejo parroquial de Santa María della Cella, en Sampierdarena (Génova) ${ }^{1}$ (figs. 1 y 2 ).

Giacomo Antonio Ponzanelli había nacido en Carrara hacia el año 1654 y, al parecer, se traslada a Génova a los once años de edad. Allí su padre le coloca de aprendiz en el taller de Filippo Parodi, en el que el joven adolescente aprendió toda la técnica de la escultura en mármol y en madera, viviendo en la casa del maestro con una familiaridad que le llevará a desposar en 1680 a María, una de sus hijas, con la que tendrá al menos ocho hijos, uno de ellos, el séptimo, Domenico seguirá la estela del padre en el manejo del mármol. A lo que parece Filippo Parodi prefería la talla de la madera a la del mármol y las obras talladas en esta piedra a menudo se confiaban a sus discípulos en su bien nutrido taller, en el que sobresalieron Domenico Parodi, Franchesco Biggi y de manera especial G. A. Ponzanelli. Como afirma su biógrafo Venancio Vellon Belloni, de quien tomamos estos datos, "todos ellos hicieron propia... la 'maniera' del maestro por lo que a menudo es difícil salir de la duda"2.

El modelo del Parodi, mide exactamente la misma altura, y antes de su llegada a la parroquia de Santa María della Cela en Sampierdarena presidió una capilla privada, de ahí sus modestas proporciones y lo refinado de su técnica, y tiene su punto de arranque en las Inmaculadas Brigniole de la iglesia dell'Albergo dei poveri de Génova y sobre todo en la Inmaculada Lomellini del oratorio de San Filippo Neri de la misma ciudad, de Pierre Puget. Muy cercana es también, aunque menos movida, la otra Inmaculada de Filippo Parodi de la iglesia delle Brignoline di Marassi ${ }^{3}$.

No obstante y, a pesar de la total dependencia de esta Inmaculada del Ponzanelli, que hoy publicamos, con respecto a la de su maestro Filippo Parodi de Santa María della Cella, hay diferencias de técnica claramente apreciables. La Inmaculada del Parodi es de técnica más refinada y rica, mostrando además un mayor claroscuro, los cinceles han penetrado más profundamente y alcanza grado de gran refinamiento, como en la mano que con un solo dedo parece sostener un pañuelo o en el enlace de uno de los cuernos de la media luna con el borde del manto, creando unas formas y perfiles plenamente rococós. La nube sobre la que María se alza es también de perfiles mucho más definidos y mayor claroscuro y faltan en la del Ponzanelli, uno de los dos

* Este trabajo forma parte de un proyecto de investigación financiado por la DGES (PB 98-0708). Queremos agradecer su desinteresada colaboración para este artículo al anticuario José A. Cámara de Juan, de Madrid.

${ }^{1}$ Catálogo Oficial de Feriarte, Feria Internacional de Arte y Antigüedades, Madrid, 2004, p. 185.

2 Vellon Belloni, Venancio, La Grande Scultura in marmo a Genova (Secoli XVII e XVIII), GBG, Genova, 1988.

${ }^{3}$ Catálogo de la Exposición Pierre Puget (Marsiglia 1620-1694). Un Artista Francese e la Cultura Barocca a Genova, Museo des Beaux-Arts di Marsiglia, Electa, 1995. 


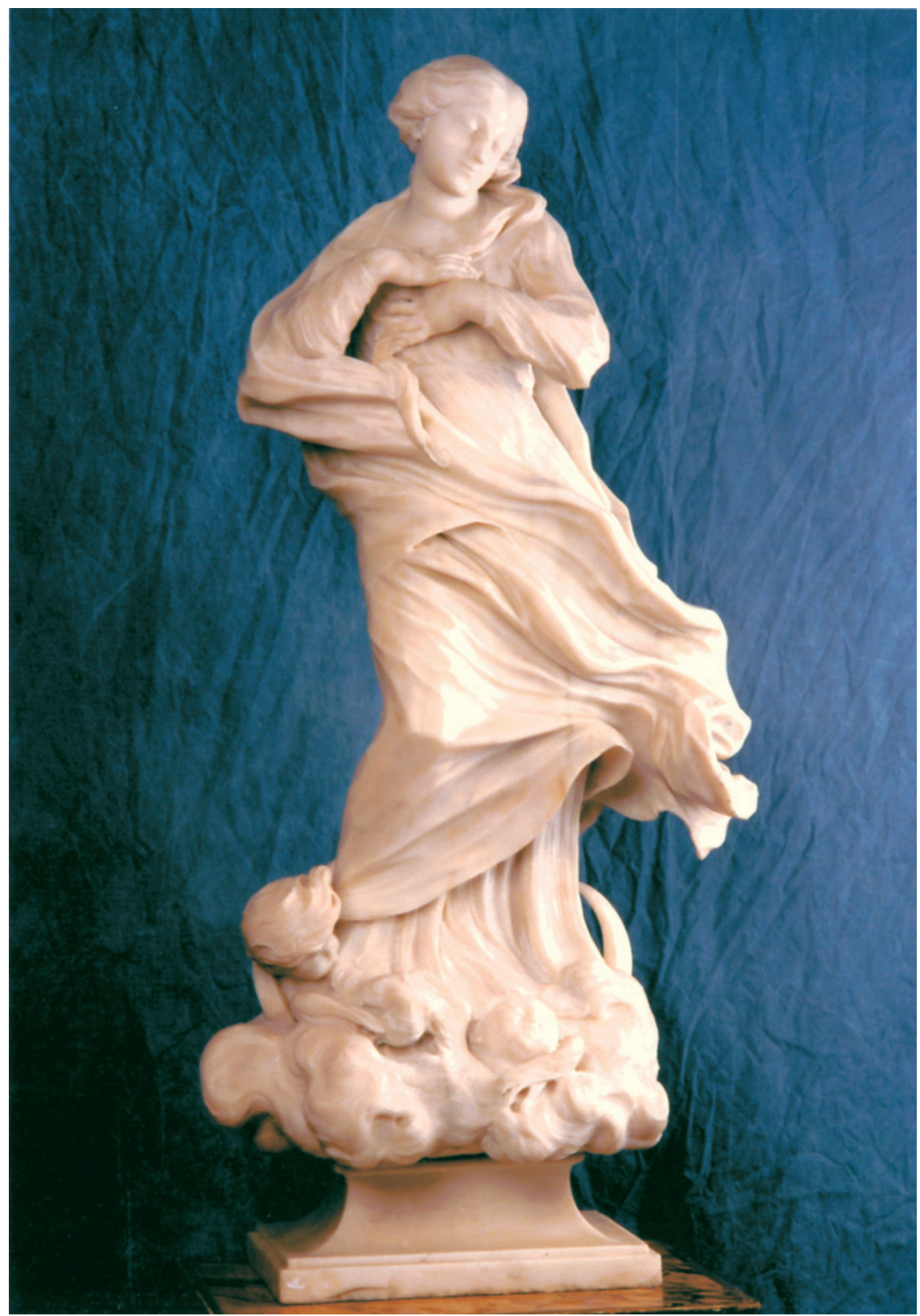

Fig. 1. Giacomo Antonio Ponzanelli. Inmaculada. Comercio Anticuario. 


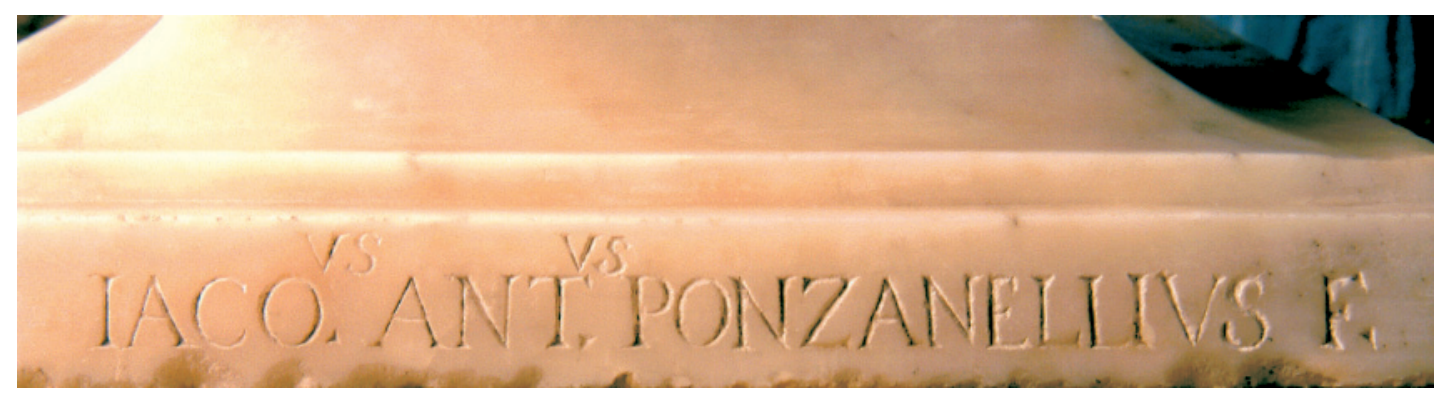

Fig. 2. Firma de Giacomo Antonio Ponzanelli.

putti que forman una pareja en su modelo y el pie de la Inmaculada que se apoya en uno de ellos. Por lo demás todas las formas resultan más indefinidas e imprecisas como vistas a través de una fina neblina. La firma del escultor en estos términos "IACO.us ANT.us PONZANELLIUS F." aparece claramente tallada en una de las molduras de la peana.

La doctora María Luisa Tárraga estudió, hace ya algunos años, en un interesantísimo artículo, cómo la Inmaculada de Parodi de la iglesia de Sta. María de la Cella en Sampierdarena fue el modelo seguido en Roma por el escultor español Isidro Carnicero del que envió un precioso boceto en barro a la Real Academia de San Fernando de Madrid que le valió el ser nombrado "Académico de Mérito por la Escultura" y cómo este mismo modelo fue adoptado por el valenciano Manuel Tolsá en sus Inmaculadas realizadas para diversos lugares de México, casi todas, con la excepción de la tallada para la Iglesia Profesa de los Jesuitas, con escasísimos variantes. La misma autora hace hincapié en cómo ya el profesor Angulo Iñiguez apuntaba que la técnica de Tolsá se veía en estas Inmaculadas "más de una formación barroca que neoclásica"

Este tipo de Inmaculadas penetró también en España por otros varios conductos, en ocasiones con la llegada de escultores de formación genovesa a España y seguidores de Pierre Puget, como es el caso del marsellés Antonio Dupar ${ }^{5}$ o por la importación de esculturas genovesas a la península ${ }^{6}$.

Desgraciado, y en parte inexplicable, ha sido el hecho de que la obra no haya sido adquirida en España y ha sido vendida, con todos los permisos de exportación en regla, a un anticuario italiano. El patrimonio español ha visto así perdida la adquisición de una obra bellísima más del Ponzanelli que hubiera enriquecido notablemente el patrimonio de este escultor en España, presente en las Comunidades madrileña ${ }^{7}$, valenciana ${ }^{8}$ y andaluza.

JUAN NicOlaU CASTRO Doctor por la Universidad Autónoma de Madrid

\footnotetext{
4 Tárraga Baldo, María Luisa, "España y América en la Escultura Cortesana de la Segunda Mitad del XVIII: Corrientes Recíprocas de Influencia”, en Relaciones Artísticas entre España y América, CSIC, Madrid, 1990, pp. 217-272.

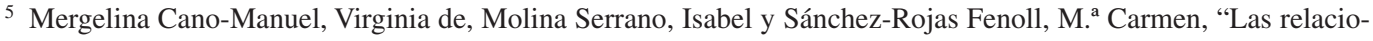
nes entre Francisco Salzillo y la Escultura del siglo XVIII", Catálogo de Exposición Francisco Salzillo y el Reino de Murcia en el Siglo XVIII, Murcia, 1984, pp. 127-142.

${ }^{6}$ Aranda Linares, Carmen, Hormigo Sánchez, Enrique y Sánchez Peña, José Miguel, Scultura Lignea Genovese a Cadice en el Settecento. Opere Documenti, Génova, 1993. Sánchez Peña, José Miguel, Escultura Genovesa. Artífices del Setecientos en Cádiz, Cádiz, 2006. López Torrijos, Rosa y Nicolau Castro, Juan, "Miscelánea sobre escultura genovesa en España", Archivo Español de Arte, n. ${ }^{\circ} 295,2001$, pp. 313-319.

7 Estella Marcos, Margarita, "El Mecenazgo de los Marqueses de Mejorada en la Iglesia y Capilla de su Villa. Su Altar-Baldaquino y sus Esculturas de Mármol. Documentos", Archivo Español de Arte, n. ${ }^{\circ} 288,1999$, pp. 469-503.

${ }^{8}$ Pérez Sánchez, Alfonso E., Valencia, Tierras de España, Fundación Juan March, 1985, p. 288.
} 